NBER WORKING PAPER SERIES

EVALUATING MENTAL HEALTH

CAPITATION TREATMENT: LESSONS

FROM PANEL DATA

\author{
Debra Sabatini Dwyer \\ Olivia S. Mitchell \\ Robert Cole \\ Sylvia K. Reed
}

Working Paper 5297

\author{
NATIONAL BUREAU OF ECONOMIC RESEARCH \\ 1050 Massachusetts Avenue \\ Cambridge, MA 02138 \\ October 1995
}

The authors are grateful for comments from John Abowd, Larry Blume, David Card, Ron Ehrenberg, Thomas Dunn, Maria Hanratty, Robert Hutchens, George Jakubson, Marcus Rebick, Graciella Viturro, and Martin Wells. Financial support for this research was provided by the National Institute of Mental Health under a grant to the University of Rochester Medical School, Cornell University, and The Wharton School. Opinions are our own. This paper is part of NBER's research program in Health Care. Any opinions expressed are those of the authors and not those of the National Bureau of Economic Research.

(ㄷ) 1995 by Debra Sabatini Dwyer, Olivia S. Mitchell, Robert Cole and Sylvia K. Reed. All rights reserved. Short sections of text, not to exceed two paragraphs, may be quoted without explicit permission provided that full credit, including $\odot$ notice, is given to the source. 


\title{
EVALUATING MENTAL HEALTH CAPITATION TREATMENT: LESSONS \\ FROM PANEL DATA
}

\begin{abstract}
The paper evaluates a capitation-financed system of mental health services delivery developed in Rochester, New York. Cost/benefit analysis of the treatment program is implemented on three years of data using program evaluation techniques. Patient outcomes are compared across randomly assigned study groups as well as across enrollment status. The analysis implements difference-in-difference econometric techniques recently developed in the labor economics literature to control for potentially non-random attrition as well as selective noncompliance. We find that patients enrolled in the capitation program do experience significantly lower costs without becoming sicker, even after controlling for attrition and sample selection.

Debra Sabatini Dwyer

Center for Policy Research

426 Eggers Hall

Syracuse University

Syracuse, NY 13244-1090

Robert Cole

Department of Psychiatry

University of Rochester

300 Crittenden Boulevard

Rochester, NY 14642

Olivia S. Mitchell

Department of Insurance and Risk Management

Wharton School

University of Pennsylvania

307 Colonial Penn Center

3641 Locust Walk

Philadelphia, PA 19104

and NBER

Sylvia K. Reed

Department of Psychiatry

University of Rochester

300 Crittenden Boulevard

Rochester, NY 14642
\end{abstract}


Health insurance policies often do not fully cover mental health treatment, despite the fact that mental health problems tend to be long-term, often involve institutionalization, and frequently imply high cost. Even when health insurance coverage is available for mental health problems, it typically covers only inpatient care, so that problems may remain untreated until expensive institutionalization is required. These policies directly contradict evolving medical practice which emphasizes keeping patients out of the hospitals, and also run counter to deinstitutionalization trends resulting from state funding cuts for mental hospitals over the last 25 years (Babigian et al., 1991).

This tension is particularly troubling since, if not properly treated, mental health disorders negatively affect social and individual welfare in many ways. Society bears the costs of crime and homelessness that can result from untreated mental illness, as well as welfare transfers necessary to sustain those unfit to work. Productivity losses may also result from the inability of the mentally ill to work; losses that might have been avoided by earlier preventative treatment. Other costs of negligence in the treatment of mental illness are the burdens placed on families and friends, as well as the direct costs borne by the patient. Rather than a systematically planned reimbursement system, however, we now face one assembled piecemeal.

An alternative treatment mode gaining favor in policy circles is a capitation-financed system, where mental health agencies receive an annual rate per patient served, in place of the traditional prospective payment system (PPS) of fee-for-service coverage for hospital stays. Mental health capitation systems, when linked to community support services as a substitute for hospitalization, have been touted by several researchers as more effective and less costly than the alternative (Babigian et al., 1991; Bacharach and Lamb, 1989; Hadley et al., 1989; 
Keisler and Morton, 1988). Nevertheless, though these types of systems are becoming popular nationwide, little scientific evidence is available on differences in overall cost, as well as benefits. In the non-mental health arena, studies have found a $40 \%$ lower rate of hospital admissions under capitation, (Manning et al., 1984; Luft, 1981), and reduced resource utilization once people are hospitalized (Johnson et al., 1989).

Two principal problems have been identified as relevant to those designing capitation delivery systems for mentally ill patients (Babigian et al., 1991). One issue is that mentally ill patients receiving community-based treatment are often cared for by more than one provider, which can lead to discontinuous and possibly disruptive care. It is possible that a capitated treatment plan in the community would alleviate this problem, since the responsible agency has incentives to coordinate efforts and effectively manage patients' illnesses. Service coordination and integration are a natural outcome of capitation-payment systems, features considered to be essential for improving care (Lehman, 1989). A second problem specific to mental health and capitation is that such a system may encourage the substitution of less expensive services for more expensive hospitalization (Hadley et al., 1989). This could be beneficial to patients inasmuch as the enrolling agencies have incentives to reduce the probability of patients becoming severly ill. Agencies will have incentives to actively seek out patients who are not keeping up with treatment and will provide continuous outpatient treatment; as a result, the more expensive hospitalization may be less necessary (Department of Health and Human Services, 1980). 


\section{Previous Capitation Efforts}

Several states and localities have implemented mental health capitation systems for their seriously mentally ill population over the last decade. However relatively little analysis of costs and benefits has been undertaken. A mental health capitation program for the general population was explored by Manning and Wells (1987) using data from the Rand Health Insurance Experiment. Whether these figures are comparable to those relevant for the seriously mentally ill is open to question. Rhode Island was one of the first states to implement such a program beginning more than a decade ago. Unfortunately, data are not available to access the impact on patient outcomes; though much has been learned regarding program implementation and operation (Christianson \& Linehan, 1989). Utah and California have implemented prepaid mental health plans where outpatient services to Medicaid patients were provided by community mental health centers, but again evaluation is in the early stages (Christianson and Gray, 1994; Hargreaves, 1992).

A different approach was followed by Massachusetts which in 1992 contracted with a private company to manage the mental health care of Medicaid recipients. There the emphasis was on cost-savings, to be achieved through a shift from institutionalization to outpatient care. Initial results show that hospitalization remained stable after the first year, but length of stay declined by about $13 \%$, and outpatient care declined as well (Fendell, 1994). While inpatient mental health expenditures fell, crisis intervention expenditures rose, which could indicate worsening of conditions (Fendell, 1994). A more sophisticated evaluation analysis was undertaken in Hennepin County, Minnesota by Lurie et al. (1992). That project sought to determine the effect of capitation on the health of the chronically 
mentally ill, which it accomplished by random assignment of more than 700 chronically mentally ill Medicaid patients to prepaid care versus fee-for-service care. The analysis found no significant differences in general health outcomes or psychiatric symptoms between prepaid and fee-for-service groups one year into the study, but did find some worsening in the psychological scores by the end of the second year. Two limitations of this work are explored further in our analysis below. First, the Minnesota study did not conduct a costeffectiveness analysis. Second, that study did not account for voluntary disenrollment and attriton. Attrition at the end of the first year in the Lurie et al. sample was low ( $96 \%$ response rate), but by the end of the second year it was much higher (only $50 \%$ of the experimental group remained in the study, and $44 \%$ of the control group). Since attrition was higher for the control group, it is possible those who remained in the study were healthier, thereby biasing results. Below, we focus on how attrition may bias results.

\section{The Rochester Experiment}

New York State funded inpatient mental hospital services for hospitalized mentally ill patients throughout the late 1980's. In the Rochester area, five community mental health centers (CMHC's) provided outpatient services for patients released from the mental hospital on a fee-for-service (or deficit reimbursement) basis. Beginning in 1989, an experimental capitation program was offered to a population of seriously and persistently mentally ill patients. Known as the Capitation Payment System (CPS), it was designed to cost-effectively shift mental health treatment from the state hospital to community-based programs.

In the capitation experiment, the CMHC's contracted with New York State to care for specific chronic mentally ill patients using a prepaid capitation payment system based on the 
patient's prior use of mental hospital services. The experiment required the CMHCs to become accountable for the costs of services rendered to patients in the community or in the mental hospital. The purpose of the experiment was to create financial incentives for CMHCs to reduce hospitalization and provide comprehensive, community-based care for patients in a cost-effective manner. The experiment thus responded to the national call for deinstitutionalization of the chronically mentally ill while controlling health care costs.

In collaboration with this experiment, the University of Rochester Medical School collected data on a set of severely and persistently mentally ill patients in 1989 ("baseline") and again annually for two years. The study team, funded by the National Institute of Mental Health, issued a preliminary report on first-year information concluding that the capitation program lowered costs without sacrificing patient well-being (Babigian, et al., 1991). The purpose of this paper is to re-evaluate program costs and benefits using all three data points. Most importantly, the panel data set permits us to evaluate issues of non-random sample attrition and selective disenrollment by providers, topics which could not be well-addressed with a single follow-up survey.' Specifically, the goal is to determine whether the capitation program continued to be less costly to manage over time as compared to the traditional treatment system, and whether hospital recidivism declined for the experimental group patients compared to the control group, after controlling for sample attrition.

The statistical analysis undertaken borrows from the labor economics literature on worker training programs and program evaluation. As with any program evaluation involving

\footnotetext{
'A preliminary follow-up study by Reed. et al. (1992) evaluating the three years finds similar cost savings at no benefit loss. However that study does not control for selective non-compliance and attrition, which are the focus of this analysis.
} 
human subjects, it becomes important to clearly understand how the control and experimental groups were selected (Heckman and Hotz, 1989; Ashenfelter and Card, 1985; Abowd, 1983). By sample design, patients in this study were initially randomly assigned (Babigian, et al., 1991), but methodological problems arose because of voluntary non-participation in the CPS program after assignment. To understand the effect of capitation treatment versus the traditional treatment, therefore is may be important to compare those in the experimental group who enrolled for treatment with those who did not, from both groups. Quite possibly those who enrolled were not a random subsample of the population, and this must be acknowledged in the evaluation analyses. In this way the sample design resembles problems studied by economicsts such as Ridder (1990) who studies non-random attrition in multi-wave panel data on labor force participation.

These issues are considered in order. Sections I - III provide background, model definition, and hypotheses. Section IV reports results using the experimental and control groups to evaluate treatment effects. Specifically, we determine whether the capitation program continued to be less costly to manage over time as compared to the traditional treatment system, and whether hospital recidivism declined for the experimental group patients compared to the control group after controlling for attrition. In Section $V$ we introduce and model selective non-participation, and address similar hypotheses comparing the enrolled with the non-enrolled. To preview our findings, we conclude that the capitation program cost less and yielded similar outcomes with respect to patient well-being. Controlling for attrition enhances the measured effectiveness of the treatment mode. 


\section{Experimental Design}

Seriously mentally ill non-criminal patients released from the Rochester psychiatric hospital during the 1987-8 baseline period were identified as eligible for CPS mental health care treatment. Of these, 605 were contacted by the study group, 422 provided completed protocols and were included in the experiment, and 227 patients were identified as requiring "continuous" care: they had experienced over 270 inpatient hospital days during the previous 3 years. $^{2}$ Of these 227 Continuous patients (a/k/a "Intent to Treat" group), 74 were then allocated randomly to a Control group (C group) and 153 to the Experimental group (E group) at the experiment's outset.

Costs and benefits for these patient groups were collected at baseline and thereafter annually for two years. Because this patient population was diagnosed as seriously and persistently mentally ill, members worked less and were less independent than the somewhat healthier patient populations examined by Weisbrod (1980). As a result, only slight monetary benefits (patient earnings) were anticipated from the treatment. Non-monetary benefits were assessed using scores on a range of psychological tests developed by the psychiatric group overseeing the program. Data collected included information on clinical symptomatology, level of functioning, quality of life, family burden, addiction, and resource utilization. In this study we focus on six summary measures of clinical symptoms, quality of life, and psychological well-being, developed by the Rochester mental health team (Babigian, et al., 1991).

\footnotetext{
${ }^{2}$ Patients with fewer days were also included in the Rochester experiment but are not the focus of this paper since capitation agencies did not bear their hospital costs. Therefore agencies had relatively little incentive to keep them in the community (Babigian, et al. 1991).
} 
Patient interviews first took place at baseline and then were repeated annually. Information on psychological and social outcomes, available for most but not all of the patients, was gathered using face-to-face interviews. Some patients could not be, or were not, fully surveyed in both years 1 and 2. A "brief" survey instrument was used in cases where patients were too sick or too uncooperative to complete the full protocol. In some cases, no interview was possible, so available data were taken from records of hospital and clinic. Censoring due to nonresponse is offset by having a special cross-agency database (called the "System Data File" or SDF) which tracked all patients as they used services from community mental health agencies and mental hospitals cooperating with the program in the Rochester area.

\section{Model and Hypothesis}

Our evaluation of the Rochester capitation payment experiment builds on work by Weisbrod (1981) who conducted one of the first economic cost-benefit analyses of a mental health program twenty years ago in Wisconsin. There, community-based programs were found to be preferred to hospitalization for the mentally ill, though that program did not involve a prepaid or capitation financing system. The Rochester experiment, by contrast, was the first to implement a capitated mental health treatment mode and to follow patients for two years following implementation.

The central hypothesis of the present study is that the Experimental group treatment produced somewhat greater benefits as compared to traditional treatment, without increasing costs imposed on health care payers, families and the community. Costs are categorized into mental health inpatient and outpatient treatment, substance abuse, medical care, social and 
community burdens, and negative psychological outcomes for the patient. Benefits include earnings which are monetizable, and psychological benefits which are non-monetary. In particular we posit that:

$$
y_{i s}=\beta^{\prime} x_{i 0}+d_{i} \alpha_{i}+u_{i s}
$$

where $\mathrm{i}=$ observation number

t $\quad=$ time period

$\mathrm{y}_{\mathrm{it}} \quad=$ cost or benefit outcomes

$\mathrm{x}_{\text {it }} \quad=$ demographic variables and baseline health status

$\mathrm{d}_{\mathrm{i}} \quad=1$ if in Experimental group

$=0$ if in Control group

$\mathrm{u}_{\mathrm{it}} \quad=$ random disturbance.

In this framework, the central hypothesis is that $\alpha_{1} \leq 0$ for costs and $\alpha_{1} \geq 0$ for benefits.

Beyond this central hypothesis, additional factors may be examined using the two-year panel aspect of the data. One is that Control (C) group patients are expected to show continuing or even increasing incidence of hospitalization over time, while it was expected that the Experimental (E) group patients maintained in a community setting would be expected to continue to improve over time. Also of interest is the time path of costs and benefits over the two years of the study, since no prior mental health experiment has evaluated treatment effects beyond a single year.

Data Censoring and Attrition Bias. The different levels of data available for patients in the dataset required that the intent-to-treat sample be divided into subsets, according to the extent of censoring on monetary and psychological outcomes. Because using smaller subsets might yield biased cost/benefit patterns, the possibility of nonrandom censoring patterns must be tested. For instance, patients in the "full information" subset might have been healthier 
and less likely to require hospitalization since they were more capable of completing full surveys. A related question is whether attrition and censoring patterns across study groups (C and E) were the same. We examine this issue using econometric models devised by Hausman and Wise (1979) and Ridder (1992), who employ maximum likelihood to correct for such bias, allowing for "history dependence". In our context, this means that someone who attrited from and then re-entered the experiment might be more likely to attrite again.

The sample censoring process over the two-year experiment is depicted in Figure 1. Subset 1 includes all of the observations carried on the agency system data file. Note that about $90 \%$ of the original intent-to-treat group still appears in year 2 . Subset 2 includes patients who completed at least a brief survey protocol ( $79 \%$ in year $1,72 \%$ in year 2 ). Subset 3 is the smallest, representing patients capable of providing a full survey protocol (65\% in year $1,53 \%$ in year 2 ). In all cases, attrition appears to be slightly higher for those not receiving the capitation treatment: the E group had a $92 \%$ participation rate for Subset 1 , compared to $86 \%$ for the $C$ group (the figures for Subset 2 are $73 \%$ and $69 \%$ respectively, and for Subset 3,56\% and 50\%). The attrition rates appear similar in the raw data, but multivariate analysis is required to determine if they were truly random.

Variables Used In Analysis

The $(6 \times 1)$ vector of cost and benefit outcomes examined in this study is as follows:

\section{Dep. Variable Description}

Inpatient Days Measures the portion of a year a patient spent institutionalized. The hypothesis is that hospital recidivism declined by more for the Experimental group compared to the Control group (available for Subset 1 only). 
Total Mental Health Costs

Patient Earnings

Global

Adjustment Scores (GAS) ${ }^{5}$

NEWSANS

Global Life Satisfaction ${ }^{7}$

All monetizeable mental health costs, measured in thousands of 1989 dollars. $^{3}$ These were expected to decline over time for the Experimental group relative to the Control group (available for Subset 1 only).

Imputed by multiplying annual hours of work by the minimum wage. Experimental patients were expected to be healthier, to spend more time as outpatients in the community, and therefore to be more productive in the labor market (available for Subset 2 only).

A psychological test score ranging between 0 and 100 , and increasing with psychological health. Experimental group patients were expected to outperform their Control group counterparts (available for Subset 2 only).

The number of moderate to negative psychological symptoms the patient conveyed during in-person interviews. This variable, which is is negatively correlated with psychological health, was expected to be lower for Experimental group patients (available for Subset 2 only).

A composite measure of overall life satisfaction collected from face-to-face interviews. Experimental group patients were expected to spend more time in the less restrictive community setting, get preventative treatment, and therefore achieve a higher global life satisfaction (available for Subset 3 only).

The factors believed to influence these outcomes may be classified according to treatment, baseline health, and personal characteristics. Focusing first on the treatment factor, the following specifications are considered:

EXP

A discrete variable that equals 1 if the patient was in the Experimental group, and 0 if in the Control group.

\footnotetext{
${ }^{3}$ For a complete description of the total mental health costs components see Appendix B, derived from Reed et al. (1993).

${ }^{4}$ Since the sample consisted of severely mentally ill patients, it is safe to assume their time was not spent in higher paying careers. Of course, this variable actually measures patient hours, rather then earnings.

${ }^{5}$ Based on experimenter ratings of each subject's overall functioning using the Global Assessment Scale; See Endicott et al., 1976.

${ }^{6}$ Based on subject responses 10 the Brief Psychiatric Rating Scale (BPRS; See Overall and Gorman, 1962).

${ }^{7}$ Based on subject responses to the Quality of Life Interview (QOLI; See Lehman, 1983).
} 
ENR0 A discrete variable that equals 1 if the patient was enrolled in the capitation payment system (CPS) at baseline, and 0 if not enrolled.

DAYS Number of days enrolled in CPS per calendar year.

Baseline health measures were also included to control on fixed individual-specific

determinants of behavior that might erroneously be attributed to experimental effects unless

held constant. Of the many candidates among the survey protocol, the following are selected based on the first-year study (Babigian et al., 1991):

ALCDRUG0 A trichotomous discrete variable measuring baseline alcohol and drug addiction; equal to 1 if either addiction, equal to 2 if both, and equal to 0 otherwise. Expected effects are ambiguous. Higher values could correspond with sicker patients and outcomes could be worse. On the other hand, addiction alone may be a less severe and less costly form of mental illness than other forms.

GASPCT Baseline GAS scores range between 0 and 100\% and increase with psychological health.

SYMPTO Baseline brief psychiatric rating scale of number of moderate symptoms is negatively correlated with psychological health.

INPOPCT Annual percentage rate of hospital days at baseline.

Mean values of all variables by treatment group appear in Table 1. At baseline, the two groups were evidently comparable, though the Control group was just slightly healthier.

Over time, there was an overall improvement in all psychological measures for both treatment groups (except for earnings). This is probably due to the state-wide deinstitutionalization trenid and mental health system overhaul that accompanied the start of this experiment. After year 1, Experimental group patients outperformed Control group patients along most dimensions (except earnings, GAS scores, and global life satisfaction); by year 2, the E group outcomes were superior in all categories. Though Control group patients had $4 \%$ fewer hospital days at baseline, the E group had $18 \%$ fewer days in the hospital in year 1, and $21 \%$ 
fewer in year 2. Total year 1 mental health costs for $E$ group patients were $13 \%$ lower in year 1 , and $14 \%$ lower in year 2 .

\section{Multivariate Comparisons}

This section asks whether patients in the Experimental group were less expensive to treat and benefited more than their Control group counterparts by virtue of having received tje capitation treatment. Several different methods of answering this question are available, beginning with a model which assumes that baseline characteristics and treatment group assignment may be assumed to be independent of the random disturbance (i.e. $x_{i t}$ and $d_{i}$ are orthogonal to $\left.u_{i t}\right)$. In equation 1 , this implies $E\left(U_{i t} \mid d_{i}, X_{i t}\right)=0$ and $E\left(Y_{i t} \mid d_{i}, X_{i t}\right)=X_{i t}{ }^{\prime} \beta+d_{i} \alpha_{i}$, so linear regression on equation (1) yields a consistent estimate of $\alpha_{1}$ and $\beta$.

The results of implementing this approach appear in the first two columns of Table $2{ }^{8}$ and indicate that inpatient days were significantly lower for the E group compared to the C group in both years (by $12-13 \%$ ). This difference translates into substantial cost savings in annual mental health costs for the $E$ group in both years of $\$ 15-\$ 16,000$ per patient (in 1989 dollars), or $18-23 \%$ of total costs. Inpatient care makes up a large proportion of total mental health costs (77-84\%), though the total figures also include other medical and social costs (see Appendix A). ${ }^{9}$

\footnotetext{
${ }^{8}$ By estimating the models separately, slope coefficients are allowed to change over time (as opposed to a time variable that would allow only the intercept to change for each individual across the two years). There is no gain to running this as a system since the right hand side of both equations is identical.

These savings are slightly higher than the $\$ 11,000$ difference reported by Babigian et al. (199I) who used only year 1 data and used a slightly different sample.
} 
Selection Correction Model: Next we loosen the orthogonality restriction and allow for possible potential sample selection wherein linear regression estimates of $\beta$ and $\alpha$ may be inconsistent. ${ }^{10}$ A stochastic relationship between di and $u_{i t}$ may arise due to any individualspecific non-random decision-making process, which here we call attrition. The process driving this behavior can be expressed as an index function $I_{i}$, where $I_{i}=z_{i} \gamma+v_{i}$, and $v_{i} \perp$ $z_{i}$. The indicator variable is then defined as $a_{i}=1$ if $y_{i t}$ is observed (and $I_{i}>0$ ), and $a_{i}=0$ $\left(I_{i} \leq 0\right)$ otherwise. Linear regression on equation 1 is biased if the sample which does not attrite is nonrandom.

A technique to deal with this omitted variables bias problem has been proposed by Hausman and Wise (1979), which assumes under random attrition (or no attrition on the entire population) that the error term from equation (1) has the following properties:

$$
\begin{aligned}
& u_{i s}=\rho_{i}+w_{i j}, \quad E\left(u_{i s}\right)=0, \quad V\left(u_{i s}\right)=\sigma_{\rho}{ }^{2}+\sigma_{w}{ }^{2}=\sigma^{2} \\
& u_{i t} \sim N\left(0, \sigma^{2}\right)
\end{aligned}
$$

2

Introducing selective attrition breaks down these assumptions. Two types of potential bias from nonrandom attrition could arise due to a relationship between the omitted individualspecific variable, $\rho_{\mathrm{i}}$, and the treatment regressors. On the one hand, the entire population that remained over time could be a selectively healthier group. In this case the coefficients on the

\footnotetext{
${ }^{10}$ Specifically we allow for the following:

$x_{i t}, d_{i}$ not $\perp u_{i l}$

$\Rightarrow E\left(u_{i t} \mid d_{i}, x_{i 0}\right) \neq 0$

$\Rightarrow E\left(y_{i t} \mid d_{i}, x_{i 0}\right) \neq x_{i 0} \beta+d_{i} \alpha_{q}$
} 
baseline health variables would be biased. Since we are not interested in $\beta$ in this analysis, this does not create a particular problem. However, if $\rho_{i}$ is correlated with the treatment variable, $d_{i}, \alpha_{i}$ is biased because attrition across study groups is then nonrandom. This requires correction since $\alpha_{q}$ represents the effect of Experimental group treatment which we seek to estimate. The probability of observing $y_{i t}$ varies with its own value as well as values of the regressors. This means the probability of observing $y_{i t}$ depends on $u_{i t}$, which violates classical assumptions. Suppose $y_{i t}$ is observed if $I_{i}=y_{i t} \lambda_{1}+x_{i 0} \lambda_{2}+d_{i} \lambda_{3}+z_{i} \gamma+v_{i}$, where $z_{i}$ is a vector of explanatory variables not included in equation (1). Substituting for $Y_{\text {it }}$ yields the reduced form as follows:

$$
\begin{aligned}
& I_{i}=\left(\lambda_{1} \beta+\lambda_{2}\right) x_{i 0}+\left(\lambda_{1} \alpha_{i}+\lambda_{3}\right) d_{i}+\gamma z_{i}+v i+\lambda_{1} u_{i t} \\
& I_{i}=\pi_{1} x_{i 0}+\pi_{2} d_{i}+\gamma z_{i}+\epsilon_{i t}
\end{aligned}
$$

The probability of being in the sample is then given by probit functions:

$$
\begin{gathered}
\operatorname{pr}\left(a_{i}=1\right)=\Phi\left[\pi_{1} X_{i 0}+\pi_{2} d_{i}+\gamma Z\right] \text { and } \\
\operatorname{pr}\left(a_{i}=0\right)=1-\Phi[\cdot],
\end{gathered}
$$

where $\Phi[\cdot]$ is the unit normal distribution function. Attrition occurs if $\mathrm{I}_{i} \leq 0$. Linear regressions of outcomes by year were corrected using attrition hazard rates as proxies for $\rho_{\mathrm{i}}$, derived from the probit on $(2)^{\prime \prime}$.

\footnotetext{
"To recapitulate the model is as follows:

$Y_{i l}=\beta X_{i 0}+d_{i} \alpha_{1}+U_{u}$$$
Y_{i 2}=\beta X_{10}+d_{1} \alpha_{2}+U_{i 2}
$$$$
I_{i}=\pi_{1} X_{i 0}+\pi_{2} d_{i}+\gamma Z_{i}+\epsilon_{i 2}
$$

Probit results appear in Appendix B. The only instrument available for identification was the agency each patient was associated with. Agencies influenced enrollment decisions and also represented the service mix and quality of care each patient received, which is hypothesized to have affected the decision to remain in the Experiment group. 
Estimates of this two-stage model appear in columns 3 and 4 of Table 2. '2 Inpatient days and total mental health costs remain lower for $\mathrm{E}$ group patients in year 1 compared to $\mathrm{C}$ group patients, and treatment benefits continue into the second year. The magnitudes and significance of treatment effects on inpatient days, total mental health costs, and negative symptomatology scores are all consistent with the hypothesis that non-random attrition biases OLS parameters of treatment effects downward. For example, the two stage model implies that inpatient days were $14 \%$ lower in year 1 and $13 \%$ lower in year 2 for $E$ group patients, slightly higher than the OLS results which were probably underestimates due to the loss of sicker Control group patients. The reduction in total mental health costs for $E$ group patients was $\$ 200$ lower then the OLS year 1 effect, but $\$ 500$ larger than the OLS year 2 result. This is not surprising more attrition took place between years 1 and 2 . Once we account for attrition, E group patients show one less negative symptom then $C$ group patient, a finding that was not apparent using OLS without the correction.

Fixed Effects Model: Another way to handle attrition uses a fixed effects model recommended by Heckman and Hotz (1989), and combines first differencing as well as the difference-of-differences approach often used in the labor economics program evaluation context. This technique removes individual heterogeneity by calculating changes in . observables before and after the experiment, but focuses within each treatment group. In this

\footnotetext{
12 The model is estimated only on those who appear in the sample for the duration of the experiment. The indicator represents the probability of falling into that category. Separate probits and corrected regressions were also examined. Results were not significantly different for all but the GAS scores equation, which lost year 2 significance. In results not reported here, we also ran Tobits treating the data as left censored. Again, the results are qualitatively similar.
} 
model, selection is assumed to depend on $\rho_{\mathrm{i}}$, the unobservable individual-specific component of $u_{i s}$ that is non-random, and more specifically is correlated with $v_{i}$ or the attrition process. $^{13}$ The omitted variable bias enters though $\rho_{i}$ only, so $E\left(u_{i t}-u_{i 0} \mid d_{i}, x_{i}\right)=0$. This implies that $E\left(w_{i t}\right)=0$ and consistent estimates of the treatment effect are measured as $Y_{i t}$ $Y_{i 0}=d_{i} \alpha_{i}+\left(x_{i t}-x_{i 0}\right) \beta+\left(w_{i t}-w_{i 0}\right)$

In the current context, treatment effects are measured in terms of pre- and postprogram differences. As is evident in Columns 5 and 6 of Table 2, several estimates change. First, GAS scores become positive and significant: Experimental group patients perform 2 to 4 points better then the Control group patients. These rsults contract with those of Lurie et al. (1992) who found no significant results in first year using Minnesota data, and a worsening in second year GAS scores by performing only OLS. That analysis did not undertake attrition corrections. In other words, accounting for attrition does significantly alter results in this study. A second finding in Table 2 is that the fixed effects model shows an improvement for both years for Experimental group patients, while our earlier results showed significant reductions in negative symptoms for Experimental patients in year l only. This is unexpected since in earlier analysis (Babigian ett al., 1991), attrition between baseline and year 1 was not believed to be a substantial problem. A third result is that a significant

\footnotetext{
${ }^{13}$ More specifically, $\rho_{i}$ enters the model as follows:

$$
E\left(y_{i z}\right)=x_{i t} \beta+d_{i} \alpha_{t}+E\left(u_{i t} \mid I_{i}>0\right)
$$$$
E\left(u_{i t} \mid d_{i}, x_{i}, I_{i}>0\right) \neq 0 \text { and }
$$$$
E\left(u_{i i} v_{i}\right) \neq 0
$$$$
u_{i t}=p_{i}+w_{i s}
$$ 
difference in GAS scores appears between the two groups after purging person-effects. This supports the hypothesis that those who were sicker dropped out of the experiment during year 1 , and also that Control group patients were sicker.

One result which is robust across all models examined is the reduction in E group hospitalization and total mental health costs. During year 1, Experimental patients were hospitalized $11 \%$ less, and cost $\$ 13,000$ less, than $C$ group patients. By year 2 , the gap in hospitalization grew to $27 \%$. An additional finding evident from the last column in Table 2 is that Experimental treatment became more effective in the second year, and also, year 2 results were more affected by sample selection. A plausible explanation for this is that the $\mathrm{C}$ patients dropped out of treatment more often, and those who dropped out were more costly to treat. In other words, $\mathrm{C}$ group patients who did not receive the capitation treatment yet remained in the study were healthier and performed better, which biased downward the simple measured difference between Controls and Experimentals. In addition, the fixed-effects model suggests that attrition imparts a larger bias than in the selection-corrected model indicates. This could be because the fixed-effects model completely removes individualeffects bias, whereas modelling attrition behavior relies on an instrument from a model that may imperfectly identify individual effects.

Conclusion on Treatment Effects: After controlling for attrition bias using two different approaches, we conclude that Experimental group patients received more beneficial treatment at a lower cost than Control group patients. This is because:

- E group patients spent 11-14\% fewer days in the hospital per year, as compared to Control group patients. 
- Experimental group patients cost $20 \%$ less in both years compared to Control group patients.

- Experimental group patients outperformed Control group patients on psychological tests in both years.

There is some evidence of improved health for patients receiving the capitation treatment once individual heterogeneity is controlled.

\section{Comparing the Enrolled Vs. Non-Enrolled}

The models estimated thus far ignore the fact that only about half of the $E$ group patients received the CPS treatment, with an average of 249 days enrolled in the program in year 1, and 307 in Year 2. ${ }^{14}$ There was also some CPS treatment contamination: six C group patients were treated in year 2 in the experimental program, with 100 days enrolled on average. This happened because some of the agencies faced a surplus of funds after year 1 and decided to share the CPS benefits with a few Control group patients. As a result, treatment effect parameters may be underestimated. In this section we compare the costs and benefits of patients actually enrolled in the CPS program, with those not enrolled regardless of study group assignment. The concern, of course, is that the actually enrolled sample may be non-random because of the voluntary nature of enrollment. More specifically, enrollment status may be simultaneously determined; that is, enrolled patients could have been those

\footnotetext{
${ }^{1+}$ CPS treatment added outpatient coverage to existing inpatient care at no cost to patients. While it might seem irrational for eligible patients to refuse treatment, placing the cost risk on the agencies created a supply-side moral hazard problem. Agencies would only resort to hospitalization in extreme cases, and less expensive outpatient care would tend to be substituted where possible. Some patients might have preferred the option of institutionalization. and thus refused the capitation option.
} 
more likely to perform better than those who did not enroll, irrespective of treatment. ${ }^{15}$ If this were true, linear regression estimates of $\alpha_{\imath}$ would be biased upward because of the simultaneity of enrollment status, though they could be biased down because of attrition. The sign of the net bias is ambiguous.

This issue is explored in Table 3 by examining different models of enrollment status. Columns 1 and 2 report the results of linear regression using enrollment status as the explanatory variable in place of treatment group. As expected, the magnitudes of the enrolled treatment effects are larger than the measured experimental effects. The treatment group advantage in inpatient days and total mental mental health costs more than doubles compared to the non treatment group, and the pattern persists over time. Year 1 magnitudes are higher in the OLS model, and in addition, GAS scores become significant for the model using enrollment.

Columns 3 and 4 take a different approach to modelling enrollment. Here we use a model proposed by Chamberlain (1983) and used by Jakubson (1988) to remove bias in an analysis of women's labor supply. ${ }^{16}$ The model may be rewritten in our context using a time-varying treatment variable as follows:

\footnotetext{
${ }^{15}$ If enrollment status is endogenous, it is correlated with the error term, $u_{i \mathrm{r}}$. It could be correlated through an unobserved, time-invariant, individual-specific ability variable that determines the probability of enrollment as well as the outcome, which can be removed by going within. If it moves with the time varying portion of the error, then once again we have correlated random effects.

${ }^{16} \mathrm{An}$ alternative would be 10 instrument the treatment variable to deal with the endogeneity. Unfortunately available instruments are not very good so that treatment would be measured with error. Also, the identifying instruments would be the same as those used in the attrition model, so collinearity may be a problem. The results from this corrected regression are robust in sign and significance. Magnitudes are slightly lower, implying those who enrolled were indeed healthier to begin with.
} 


$$
\begin{gathered}
y_{i t}=\beta_{0 r} r_{i 0}+\beta_{x_{i t}}+d_{i t} \alpha_{t}+\rho_{i}+w_{i t} \\
\rho_{i}=\lambda_{0} X_{i 0}+\lambda_{1} X_{i 1}-\lambda_{I} X_{i 2}-\lambda_{3} d_{i t}+\lambda_{t} d_{i 2}+\gamma Z_{i}+v_{i} \\
E\left(a_{i}, U_{i t}\right)=0
\end{gathered}
$$

The reduced form of each equation is as follows:

$$
\begin{aligned}
& Y_{i 1}=\left(\beta_{01}+\lambda_{0}\right) X_{i 0}+\left(\beta+\lambda_{1}\right) X_{i 1}+\lambda_{2} X_{i 2}+\left(\alpha_{1}+\lambda_{3}\right) d_{i 1}+\lambda_{1} d_{i 2}+\gamma Z_{i}+v_{i}+w_{i 1} \\
& Y_{i 2}=\left(\beta_{02}+\lambda_{0}\right) X_{i 0}+\lambda_{1} X_{i 1}+\left(\beta+\lambda_{1}\right) X_{i 2}+\lambda_{3} d_{i 1}+\left(\alpha_{2}+\lambda_{1}\right) d_{i 2}+\gamma Z_{i}+v_{i}+w_{i 2}
\end{aligned}
$$

Identification of the $\alpha_{1}$ 's comes from the days enrolled variable. Now $\lambda_{3}$ and $\lambda_{4}$, which represent the bias in the coefficients on $d_{i v}$, are identified and can be purged. Included in $Z_{i}$ is the same attrition hazard rate from the probit model in Table 2, to avoid the potential attrition bias as well. ${ }^{17}$

In this framework, patients enrolled for CPS treatment were hospitalized $42 \%$ less often (153 days), and cost $70 \%(\$ 45,800)$ less than those who received traditional treatment (Table 3, Columns 3 and 4). Corresponding figures for year 2 were $53 \%$ less hospitalization (194 days) and cost savings of about $75 \%(\$ 63,000)$. In general, this model shows a much larger impact on hospitalization and costs for both years compared to OLS and fixed effects approaches. The significant difference in attrition behavior between the enrolled and non-

\footnotetext{
${ }^{17}$ Probit results appear in Appendix A. A specification test for this structure on the relationship between $\rho_{i}$ and treatment is not possible without an additional year of data. The only testable restrictions across equations were on comparisons of the coefficients on $x_{i 0}$. and $z_{i}$. These restrictions fit the data.
} 
enrolled may mean that those who enrolled had more incentive to remain in the experiment, whereas those who dropped out were more likely very ill non-enrolled who are more sick. ${ }^{18}$

The fixed effects model uses enrollment status in place of the treatment variable, which assumes that the probability of enrolling is determined by individual specific heterogeneity which is time-invariant. The results (Table 3 , Columns 5 and 6 ) show that those enrolled for CPS treatment received $26 \%$ less hospitalization than those receiving traditional treatment in year 1 , and $35 \%$ less in year 2 . The fact that year 1 effects are lower then the results in the first two columns supports the hypothesis that the enrolled were selectively healthier. The fact that the year 2 effect is much higher than the linear model results in column 2 implies that nonrandom attrition bias does contaminate treatment effects. Total mental health costs are lower then earlier results after controlling for heterogeneity. Between years 1 and 2, those enrolled cost $\$ 31,000$ less than the non-enrolled, still a sizeable difference in costs. The decline in magnitude (compared to Columns 1 and 2) could imply that those enrolled were likely to cost less regardless of treatment. GAS scores, which represent the psychological health of the patients, were also significantly higher in magnitude.

\footnotetext{
${ }^{18}$ There were more people enrolled for a greater number of days in year 2 . The selection problem could also become less significant in year 2 since enrollment expanded. Those who were newly enrolled in year 2 could have also been sicker, which would explain the higher magnitudes.

An alternative story would be that those who enrolled were actually selectively sicker, so that the sign of the bias would be the same as the attrition bias. Baseline means show fewer hospital stays and higher test scores for those enrolled, which is inconsistent with this alternative story

Estimating the Chamberlain model with controls on the probability of being in the sample for both years has little effect on year 2 results, but increases the magnitudes of year 1 results to be on par with those of year 2's. This suggests that non-participation in year 1 is important, and that that those in the non-enrolled category who did participate were healthier.
} 
This further supports the hypothesis that attrition contaminated in the OLS results, where these effects were not significantly different from zero. We would expect treatment might take longer to improve mental health than cost of treatment, and these results confirm that expectation as weil.

Conclusion on CPS Treatment Effects: After controlling for potential non-random attrition and program participation, the results indicate that the capitation program patients cost less to treat, but maintained the same health outcomes as those receiving traditional treatment. This conclusion is based on the following findings:

- On average, CPS enrolled patients had at least $26 \%$ fewer hospital days in year 1 , and between $30-50 \%$ fewer days in year 2 .

- On average, CPS enrolled patients cost $70 \%$ less in year 1 , and $75 \%$ less in year 2 .

- Enrolled patients demonstrated no worse health outcomes and in some models showed improvements through higher GAS scores.

\section{Conclusions}

The results of this analysis suggest that a capitated community-based mental health treatment program can prove cost-effective while maintaining, if not improving, the mental health of a group of severely mentally ill adults. A carefully designed experimental program in Rochester, NY afforded an unusual opportunity to control on sample attrition and endogenous enrollment patterns. Our analysis shows that attrition models enhance the measured effectiveness of the capitation treatment mode. Results of models which control on enrollment also indicate that participation in the CPS treatment reduced costs considerably. 
Future evaluation studies in the mental health field will benefit from additional integration of panel data analytic techniques developed in the labor economics literature of the last decade.

Improvements in mental health treatment that place the severely mentally ill in a community setting with no negative impact on their health have significant implications for welfare and employment policies as well as health policy. Being in a community setting may increase productivity of the mentally ill through more preventative and less intrusive treatment possibly resulting in fewer welfare transfers and a more productive population.

Two caveats must be noted before concluding that capitation programs for severely mentally ill patients will be cost effective for all communities. First, this treatment program required extensive inter-agency cooperation which was feasible in Rochester, but might be more difficult elsewhere. Second, a community considering capitating mental health delivery must recognize that some patients will not participate and will continue to require traditional hospitalization. Nevertheless, the bottom line is that capitation produced cost savings of at least $20 \%$ and at best $75 \%$ per year, without significant curtailment in psychological wellbeing. 
Figure 1

Sample Censoring Process, Percent of Intent-to-Treat Group Available for Both Years, By Group

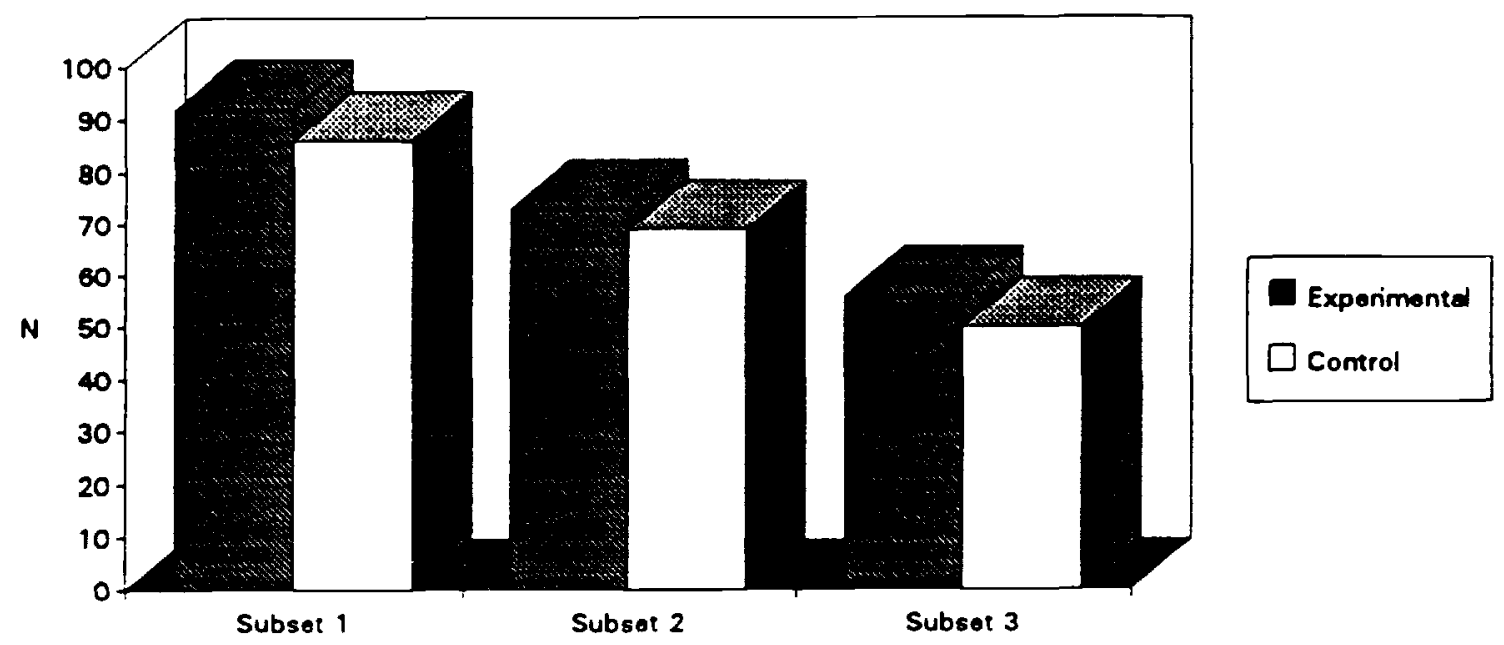

Note: Data come from the SDF and the Resource Index (RI) and the subsets are set up as follows:

Subset 1: all observations carried on the agency system data file, which electronically tracks utilization.

Subset 2: includes patients who completed at least a brief survey protocol.

Subset 3: includes patients who completed full survey protocol. 


\begin{tabular}{|c|c|c|c|c|c|c|}
\hline \multirow[b]{2}{*}{ Variable } & \multicolumn{2}{|c|}{ Total } & \multicolumn{2}{|c|}{ Control } & \multicolumn{2}{|c|}{ Experimental } \\
\hline & $\mathbf{N}$ & MEAN & $\mathbf{N}$ & MEAN & $\mathbf{N}$ & MEAN \\
\hline $\begin{array}{l}\text { Hospital Inpatient Days } \\
\text { Baseline } \\
\text { Year } 1 \\
\text { Year } 2\end{array}$ & $\begin{array}{l}227 \\
211 \\
204\end{array}$ & $\begin{array}{l}219.2 \\
191.2 \\
127.2\end{array}$ & $\begin{array}{l}74 \\
67 \\
64\end{array}$ & $\begin{array}{l}213.7 \\
218.2 \\
148.4\end{array}$ & $\begin{array}{l}153 \\
144 \\
140\end{array}$ & $\begin{array}{l}221.9 \\
178.1 \\
117.0\end{array}$ \\
\hline $\begin{array}{l}\text { Total MH Costs (1988 \$) } \\
\text { Year } 1 \\
\text { Year } 2\end{array}$ & $\begin{array}{l}211 \\
204 \\
\end{array}$ & $\begin{array}{l}87,684 \\
65,747 \\
\end{array}$ & $\begin{array}{l}67 \\
64 \\
\end{array}$ & $\begin{array}{l}97,488 \\
72,774 \\
\end{array}$ & $\begin{array}{l}144 \\
140 \\
\end{array}$ & $\begin{array}{l}84,550 \\
62,349 \\
\end{array}$ \\
\hline $\begin{array}{l}\text { Earmings (1988 \$) } \\
\text { Year } 1 \\
\text { Year } 2\end{array}$ & $\begin{array}{l}153 \\
122 \\
\end{array}$ & $\begin{array}{l}573.93 \\
531.12\end{array}$ & $\begin{array}{l}67 \\
64 \\
\end{array}$ & $\begin{array}{l}616.75 \\
502.00\end{array}$ & $\begin{array}{l}144 \\
140 \\
\end{array}$ & $\begin{array}{l}553.22 \\
545.21 \\
\end{array}$ \\
\hline $\begin{array}{l}\text { GAS Scores } \\
\text { Baseline } \\
\text { Year } 1 \\
\text { Year } 2 \\
\end{array}$ & $\begin{array}{l}179 \\
173 \\
158 \\
\end{array}$ & $\begin{array}{l}38.45 \\
42.14 \\
44.35 \\
\end{array}$ & $\begin{array}{l}70 \\
58 \\
51 \\
\end{array}$ & $\begin{array}{l}38.54 \\
43.55 \\
43.24 \\
\end{array}$ & $\begin{array}{l}153 \\
120 \\
112 \\
\end{array}$ & $\begin{array}{l}38.41 \\
41.46 \\
44.86 \\
\end{array}$ \\
\hline $\begin{array}{l}\text { Negative Symptomology } \\
\text { (NEWSANS) } \\
\text { Year } 1 \\
\text { Year } 2 \\
\end{array}$ & $\begin{array}{l}173 \\
156 \\
\end{array}$ & $\begin{array}{l}2.75 \\
2.70 \\
\end{array}$ & $\begin{array}{l}59 \\
51 \\
\end{array}$ & $\begin{array}{l}3.17 \\
3.27 \\
\end{array}$ & $\begin{array}{l}119 \\
110\end{array}$ & $\begin{array}{l}2.54 \\
2.43 \\
\end{array}$ \\
\hline $\begin{array}{l}\text { Global Life Satisfaction } \\
\text { Year } 1 \\
\text { Year } 2 \\
\end{array}$ & $\begin{array}{l}148 \\
119 \\
\end{array}$ & $\begin{array}{l}4.61 \\
4.96 \\
\end{array}$ & $\begin{array}{l}52 \\
37 \\
\end{array}$ & $\begin{array}{l}4.69 \\
4.85 \\
\end{array}$ & $\begin{array}{r}101 \\
85 \\
\end{array}$ & $\begin{array}{l}4.57 \\
5.01 \\
\end{array}$ \\
\hline $\begin{array}{l}\text { Personal Characteristics } \\
\text { AGE } \\
\text { FEMALE } \\
\text { WHITE }\end{array}$ & $\begin{array}{l}227 \\
227 \\
227 \\
\end{array}$ & $\begin{array}{r}36.31 \\
0.41 \\
0.71 \\
\end{array}$ & $\begin{array}{l}74 \\
74 \\
74 \\
\end{array}$ & $\begin{array}{r}35.39 \\
0.46 \\
0.66 \\
\end{array}$ & $\begin{array}{l}153 \\
153 \\
153 \\
\end{array}$ & $\begin{array}{r}36.75 \\
0.39 \\
0.73 \\
\end{array}$ \\
\hline $\begin{array}{l}\text { Baseline Health Measures } \\
\text { Alcobol addiction } \\
\text { Drug addiction } \\
\text { Symptomotology }\end{array}$ & $\begin{array}{l}227 \\
227 \\
227 \\
\end{array}$ & $\begin{array}{l}0.22 \\
0.15 \\
4.39 \\
\end{array}$ & $\begin{array}{l}74 \\
74 \\
73 \\
\end{array}$ & $\begin{array}{l}0.21 \\
0.15 \\
4.81 \\
\end{array}$ & $\begin{array}{l}153 \\
153 \\
152 \\
\end{array}$ & $\begin{array}{l}0.23 \\
0.15 \\
4.18 \\
\end{array}$ \\
\hline $\begin{array}{l}\text { Treatment Variables } \\
\text { EXPERIMENTAL GROUP } \\
\text { ENROLLED (baseline) } \\
\text { DAYS ENROLLED' } \\
\text { Year } 1 \\
\text { Year } 2 \\
\end{array}$ & $\begin{array}{r}153 \\
71 \\
73 \\
100 \\
\end{array}$ & $\begin{array}{l}248.6 \\
203.3 \\
\end{array}$ & $\begin{array}{l}0 \\
6 \\
\end{array}$ & $\begin{array}{c}0 \\
0 \\
0 \\
99.83 \\
\end{array}$ & $\begin{array}{c}153 \\
71 \\
73 \\
94 \\
\end{array}$ & $\begin{array}{l}1.00 \\
0.46 \\
248.6 \\
306.8 \\
\end{array}$ \\
\hline
\end{tabular}

'Mean days for those enrolled. 


\begin{tabular}{|c|c|c|c|c|c|c|}
\hline \multirow[b]{2}{*}{ Outcomes } & \multicolumn{2}{|c|}{ OLS } & \multicolumn{2}{|c|}{ Corrected Reg Effects } & \multicolumn{2}{|c|}{ Fixed Effects' } \\
\hline & $\begin{array}{c}\text { Year } 1 \\
\text { (1) }\end{array}$ & $\begin{array}{c}\text { Year } 2 \\
\text { (2) }\end{array}$ & $\begin{array}{c}\text { Year } 1 \\
\text { (3) }\end{array}$ & $\begin{array}{c}\text { Year } 2 \\
\text { (4) }\end{array}$ & $\begin{array}{c}\text { Year 1 - } \\
\text { Baseline } \\
\text { (5) }\end{array}$ & $\begin{array}{c}\text { Yr 2 - } \\
\text { Baseline } \\
\text { (6) }\end{array}$ \\
\hline $\begin{array}{c}\text { Inpatieat Days } \\
\text { (\% /year) } \\
\mathrm{R}^{2}\end{array}$ & $\begin{array}{c}-0.13^{* *} \\
(0.05) \\
\mathrm{n}=206 \\
0.30\end{array}$ & $\begin{array}{c}-0.12^{* *} \\
(0.06) \\
0=199 \\
0.19\end{array}$ & $\begin{array}{c}-0.14^{* *} \\
(0.05) \\
\mathrm{n}=196 \\
0.31\end{array}$ & $\begin{array}{c}-0.13^{* *} \\
(0.06) \\
\mathrm{n}=196 \\
0.19 \\
\end{array}$ & $\begin{array}{c}-0.11^{* *} \\
(0.04) \\
\mathrm{n}=171 \\
0.76 \\
\end{array}$ & $\begin{array}{c}-0.27 * * \\
(0.05) \\
n=156 \\
0.93 \\
\end{array}$ \\
\hline $\begin{array}{c}\text { Total Mental } \\
\text { Health Costs } \\
\left(\$ 000^{\circ} \mathrm{s}\right) \\
\mathrm{R}^{2}\end{array}$ & $\begin{array}{c}-16.1 * * \\
(6.4) \\
\mathrm{n}=206 \\
0.33\end{array}$ & $\begin{array}{c}-15.2^{* *} \\
(7.36) \\
\mathrm{n}=220 \\
0.22\end{array}$ & $\begin{array}{c}-15.9^{* *} \\
(6.88) \\
\mathrm{n}=196 \\
0.34\end{array}$ & $\begin{array}{c}-15.7^{* *} \\
(7.78) \\
n=196 \\
0.21\end{array}$ & \multicolumn{2}{|c|}{$\begin{array}{c}-13.64^{2} \\
(9.88) \\
\mathrm{a}=143 \\
0.97\end{array}$} \\
\hline $\begin{array}{c}\text { Earnings } \\
(\$ 00 ' s) \\
R^{2}\end{array}$ & $\begin{array}{c}-7.51 \\
(22.97) \\
\mathrm{n}=174 \\
0.08\end{array}$ & $\begin{array}{c}-5.78 \\
(24.53) \\
D=158 \\
0.09\end{array}$ & $\begin{array}{c}-1.37^{3} \\
(2.38) \\
\mathrm{n}=142 \\
0.11\end{array}$ & $\begin{array}{c}-.76 \\
(2.51) \\
\mathrm{D}=142 \\
0.16\end{array}$ & \multicolumn{2}{|c|}{$\begin{array}{c}2.46^{4} \\
(13.32) \\
n=143 \\
0.05\end{array}$} \\
\hline Gas Scores ${ }^{3}$ & $\begin{array}{c}-1.00 \\
(1.00) \\
\mathbf{D}=172 \\
0.31\end{array}$ & $\begin{array}{c}-0.200 \\
(0.500) \\
\mathrm{D}=157 \\
0.22\end{array}$ & $\begin{array}{c}-1.10 \\
(2.00) \\
\mathrm{n}=142 \\
0.27\end{array}$ & $\begin{array}{c}2.00 \\
(2.10) \\
\mathrm{n}=142 \\
0.22\end{array}$ & $\begin{array}{c}2.23^{* *} \\
(1.11) \\
\mathrm{n}=171 \\
0.95\end{array}$ & $\begin{array}{c}4.33^{* *} \\
(1.30) \\
\mathrm{n}=156 \\
0.99\end{array}$ \\
\hline $\begin{array}{c}\text { Negative } \\
\text { Symptomatolgy } \\
\mathrm{R}^{2}\end{array}$ & $\begin{array}{c}-0.70 \\
(0.5) \\
\mathrm{n}=172 \\
0.17\end{array}$ & $\begin{array}{c}-0.54 \\
(0.5) \\
\mathrm{n}=155 \\
0.16\end{array}$ & $\begin{array}{c}-1.04^{* * *} \\
(0.51) \\
\mathrm{n}=141 \\
0.23\end{array}$ & $\begin{array}{c}-0.72 \\
(0.53) \\
\mathrm{n}=140 \\
0.16\end{array}$ & $\begin{array}{c}0.40 \\
(0.27) \\
n=171 \\
0.94 \\
\end{array}$ & $\begin{array}{c}-0.09 \\
(0.31) \\
\mathrm{n}=154 \\
0.94 \\
\end{array}$ \\
\hline $\begin{array}{c}\text { Global Life } \\
\text { Satisfaction? } \\
\mathbf{R}^{2}\end{array}$ & $\begin{array}{c}-0.30 \\
(0.3) \\
\mathrm{n}=147 \\
0.07\end{array}$ & $\begin{array}{c}0.20 \\
(0.3) \\
a=118 \\
0.08\end{array}$ & $\begin{array}{c}-0.34 \\
(0.33) \\
\mathrm{n}=98 \\
0.10\end{array}$ & $\begin{array}{c}0.20 \\
(0.28) \\
n=97 \\
0.08\end{array}$ & $\begin{array}{c}-0.20 \\
(0.19) \\
\mathrm{a}=112 \\
0.63\end{array}$ & $\begin{array}{c}0.13 \\
(0.23) \\
\mathrm{n}=89 \\
0.48\end{array}$ \\
\hline
\end{tabular}

$t \geq 1.65(<1.96), * t \geq 1.96$
OLS Treatment Models (1) and (2): $Y_{a}=d_{1} \alpha_{1}+X_{00} \beta+U_{i n}$

Selection Corrected Reg Treatment Models (5) and (6): $Y_{q}=X_{n} \beta+d a_{4}+\sigma \lambda+U_{\text {a }}$

Fixed Effects Treatment Models (3) and (4): $Y_{1}-Y_{0}=d_{1} \alpha_{1}+\left(X_{1}-X_{i d}\right) \beta+\left(w_{1}-w_{10}\right)$

\footnotetext{
'Standard errors were adjusted for degrees of freedom difference.
}

'Total mental health costs not available at baseline. This coefficient reflects treatment effect comparing the first and second year of the experiment.

'Mills ratio is significant for this equation.

'Eamings not available at baseline. The estimate reflects treatment effects comparing years 1 and 2 of the experiment.

'A GAS Score is a psychological test score ranging between 0 and 100 , and is increasing with prychological health.

This counts the number of negative symptoms the patient conveyed, negatively correlated with psychological health.

'This variable is a measure of quality of life ranging between 1 and 7 , and is increasing in satisfaction. 


\begin{tabular}{|c|c|c|c|c|c|c|}
\hline \multirow[b]{2}{*}{ Outcomes } & \multicolumn{2}{|c|}{ OLS } & \multicolumn{2}{|c|}{ Chamberlain Model } & \multicolumn{2}{|c|}{ Fixed Effects } \\
\hline & $\begin{array}{c}\text { Year } 1 \\
(1)\end{array}$ & $\begin{array}{c}\text { Year } 2 \\
(2) \\
\end{array}$ & $\begin{array}{c}\text { Year } 1 \\
(3) \\
\end{array}$ & $\begin{array}{c}\text { Yeat } 2 \\
(4) \\
\end{array}$ & $\begin{array}{c}\text { Year 1 - } \\
\text { Baseline } \\
(5)\end{array}$ & $\begin{array}{c}\text { Year } 2 \text { - } \\
\text { Baseline } \\
(6)\end{array}$ \\
\hline $\begin{array}{c}\text { Inpatient Days } \\
\text { (\%/year) } \\
\mathrm{R}^{2}\end{array}$ & $\begin{array}{c}-0.32 * * \\
(0.05) \\
n=206 \\
0.41 \\
\end{array}$ & $\begin{array}{c}-0.28^{* *} \\
(0.06) \\
\mathrm{n}=199 \\
0.26 \\
\end{array}$ & $\begin{array}{c}-0.42^{* *} \\
(0.10) \\
n=139 \\
0.49 \\
\end{array}$ & $\begin{array}{c}-0.53 * * \\
(0.16) \\
n=139 \\
0.45 \\
\end{array}$ & $\begin{array}{c}-0.26^{* *} \\
(0.05) \\
D=171 \\
0.90\end{array}$ & $\begin{array}{c}-0.35^{* *} \\
(0.07) \\
\mathrm{n}=156 \\
0.92 \\
\end{array}$ \\
\hline $\begin{array}{c}\text { Total Mental } \\
\text { Health Costs } \\
(\$ 000 \mathrm{~s}) \\
\mathrm{R}^{2}\end{array}$ & $\begin{array}{c}-35.0^{* *} \\
(6.1) \\
\mathrm{n}=206 \\
0.41\end{array}$ & $\begin{array}{c}-32.7^{* *} \\
(7.1) \\
\mathrm{n}=199 \\
0.28\end{array}$ & $\begin{array}{c}-45.82^{* *} \\
(13.4) \\
n=139 \\
0.45\end{array}$ & $\begin{array}{c}-62.94^{* *} \\
(10.5) \\
n=139 \\
0.44\end{array}$ & 1 & $\begin{array}{c}-30.65^{* *} \\
(12.83) \\
\mathrm{D}=144 \\
0.97 \\
\end{array}$ \\
\hline $\begin{array}{c}\text { Earnings } \\
(\$ 00 \mathrm{~s}) \\
\mathrm{R}^{2} \\
\end{array}$ & $\begin{array}{c}-9.22 \\
(23.20) \\
\mathrm{n}=174 \\
0.11 \\
\end{array}$ & $\begin{array}{c}1.75 \\
(24.69) \\
\mathrm{n}=158 \\
0.12 \\
\end{array}$ & $\begin{array}{c}-2.23 \\
(4.48) \\
\mathrm{n}=138 \\
0.24 \\
\end{array}$ & $\begin{array}{c}0.98 \\
(3.51) \\
\mathrm{n}=138 \\
0.28 \\
\end{array}$ & 2 & $\begin{array}{c}12.23 \\
(17.505) \\
\mathrm{a}=144 \\
0.05 \\
\end{array}$ \\
\hline $\begin{array}{c}\text { Gas Scores }{ }^{3} \\
\mathrm{R}^{2}\end{array}$ & $\begin{array}{c}2.50 \\
(1.84) \\
n=173 \\
0.31 \\
\end{array}$ & $\begin{array}{c}3.95^{* *} \\
(1.96) \\
n=158 \\
0.24 \\
\end{array}$ & $\begin{array}{c}2.13 \\
(3.53) \\
\mathrm{n}=138 \\
0.60 \\
\end{array}$ & $\begin{array}{c}1.37 \\
(2.84) \\
\mathrm{n}=139 \\
0.57 \\
\end{array}$ & $\begin{array}{c}5.02^{* *} \\
(1.63) \\
\mathrm{n}=172 \\
0.95 \\
\end{array}$ & $\begin{array}{c}5.77^{* *} \\
(1.88) \\
\mathrm{n}=139 \\
0.96 \\
\end{array}$ \\
\hline $\begin{array}{c}\text { Negative } \\
\text { Symptomatolgy } \\
\mathrm{R}^{2}\end{array}$ & $\begin{array}{c}-0.36 \\
(0.47 \\
\mathrm{n}=173 \\
0.17 \\
\end{array}$ & $\begin{array}{c}-0.10 \\
(0.51) \\
n=156 \\
0.15 \\
\end{array}$ & $\begin{array}{c}-1.36 \\
(0.85) \\
\mathrm{n}=137 \\
0.45 \\
\end{array}$ & $\begin{array}{c}-0.19 \\
(0.67) \\
\mathrm{n}=139 \\
0.43 \\
\end{array}$ & $\begin{array}{c}0.70^{*} \\
(0.40) \\
n=170 \\
0.94 \\
\end{array}$ & $\begin{array}{c}0.45 \\
(0.46) \\
\mathrm{D}=154 \\
0.94 \\
\end{array}$ \\
\hline $\begin{array}{c}\text { Global Life } \\
\text { Satisfactions } \\
\mathbf{R}^{2}\end{array}$ & $\begin{array}{c}0.24 \\
(0.28) \\
n=148 \\
0.07\end{array}$ & $\begin{array}{c}0.18 \\
(0.24) \\
D=118 \\
0.08\end{array}$ & $\begin{array}{c}0.01 \\
(0.48) \\
\mathrm{n}=118 \\
0.37\end{array}$ & $\begin{array}{c}0.30 \\
(0.38) \\
\mathrm{n}=103 \\
0.27 \\
\end{array}$ & $\begin{array}{c}-0.01 \\
(0.27) \\
\mathrm{n}=112 \\
0.54 \\
\end{array}$ & $\begin{array}{c}0.11 \\
(0.29) \\
n=89 \\
0.47 \\
\end{array}$ \\
\hline
\end{tabular}

$* t \geq 1.65(<1.96)$. * $1 \geq 1.96$

OLS Enroliment Models (1) and (2): $\quad Y_{n}=d_{1} \alpha_{1}+X_{0}{ }^{\prime} \beta+U_{n}$

Chamberlain Model $\quad$ Model (5): $\quad Y_{i 1}=\left(\beta_{1}+\lambda_{0}\right) X_{0}+\left(\beta+\lambda_{1}\right) X_{i 1}+\lambda_{2} X_{i 2}+\left(\alpha_{1}+\lambda_{3}\right) d_{i 1}+\lambda_{1} d_{2}+\gamma_{2}+\alpha_{1}+w_{i 1}$ Model (6): $\quad Y_{i 2}=\left(\beta_{3}+\lambda_{0}\right) X_{0}+\lambda_{1} X_{i 1}+\left(\beta+\lambda_{2}\right) X_{22}+\left(\alpha_{4}+\lambda_{3}\right) d_{i 1}+\lambda_{3} d_{11}+\gamma Z_{1}+\alpha_{1}+w_{i 2}$

Fixed Effects Models (3) and (4): $\quad Y_{11}-Y_{10}=d_{10} \alpha_{1}+\left(X_{1}-X_{\infty}\right) \beta+\left(w_{1}-w_{10}\right)$

'Total mental health costs were not available at baseline. This coefficient reflects the treatment effect compariag the first and scond year of the experiment.

'Eamings not available at baseline. The estimate reflects treatment effects comparing year 1 and year 2 of the experiment.

'A GAS Score is a psychological test score ranging between 0 and 100, and is increasing with psychological health.

This counts the number of negative symptoms the patient conveyed, negatively correlated with psychological health.

This variable is a measure of quality of life ranging between 1 and 7 , and is increasing in satisfaction. 


\begin{tabular}{|c|c|c|c|c|c|}
\hline Monetized Costs & S/Unit & $\begin{array}{l}\text { Control } \\
(\mathrm{n}=63)\end{array}$ & $\begin{array}{l}\text { Exper } \\
(n=138)\end{array}$ & $\begin{array}{l}\text { Control } \\
(n=63)\end{array}$ & $\begin{array}{l}\text { Exper } \\
(0=138)\end{array}$ \\
\hline $\begin{array}{l}\text { I. Residential Mental Health Care } 2 \\
\text { Community Inpatient Day } \\
\text { State Psych. Center Inpatient Day } \\
\text { Supervised Resideotial Day }\end{array}$ & $\begin{array}{ll}\text { S } & 388 \\
\text { S } & 388 \\
\text { S } & 72\end{array}$ & $\begin{array}{l}\text { S } 89,994 \\
\text { S } 438 \\
\text { \$ } 87,071 \\
\text { S } 2,484\end{array}$ & $\begin{array}{l}\$ 74,364 \\
\$ 1,034 \\
\$ 70,561 \\
\$ 2,499\end{array}$ & $\begin{array}{l}\$ 70,051 \\
\text { \$ } 1,467 \\
\$ 64,080 \\
\text { \$ } 4,504\end{array}$ & $\begin{array}{l}\text { \$ } 53,992 \\
\text { S } 2,988 \\
\text { \$ } 48,428 \\
\text { \$ } 2,576\end{array}$ \\
\hline $\begin{array}{l}\text { ח1. Outpatient Mental Health Care' } \\
\text { Clinic } \\
\text { Full visit, assessment, in-crisis } \\
\text { Brief visit and med visit } \\
\text { Outpatient visit } \\
\text { Group and family visit } \\
\text { Day treatment visit } \\
\text { Continuing treatment visit } \\
\text { Crisis visit } \\
\text { Rebabilitation } \\
\text { Rebabilitation visit } \\
\text { Sbeltered worksbop visit } \\
\text { Case management bour } \\
\text { Other support } \\
\text { Psychosocial club visit } \\
\text { On-site rebab visit } \\
\text { Transportation } \\
\text { Volunteer friend } \\
\text { Medication costr }\end{array}$ & $\begin{array}{cc}\text { s } & 111 \\
\text { \$ } & 55 \\
\text { \$ } & 69 \\
\text { S } & 44 \\
\text { \$ } & 97 \\
\text { S } & 58 \\
\text { S } & 188 \\
\text { S } & 58 \\
\text { \$ } & 36 \\
\text { \$ } & 62 \\
\text { S } & 60 \\
\text { \$ } & 6 \\
\text { \$ } & 9 \\
\text { S } & 10\end{array}$ & $\begin{array}{cc}\text { s } & 3,757 \\
\text { s } & 504 \\
\text { s } & 587 \\
\text { s } & 106 \\
\text { s } & 0 \\
\text { s } & 192 \\
\text { s } & 569 \\
\text { s } & 119 \\
& \\
\text { s } & 495 \\
\text { s } & 251 \\
\text { s } & 643 \\
& \\
\text { s } & 192 \\
\text { s } & 53 \\
\text { s } & 11 \\
\text { s } & 35 \\
\text { s } & 3,218\end{array}$ & $\begin{array}{cc}\text { s } & 5,719 \\
\text { s } & 710 \\
\text { s } & 815 \\
\text { s } & 0 \\
\text { s } & 3 \\
\text { s } & 1 \\
\text { s } & 1,009 \\
\text { s } & 154 \\
& \\
\text { s } & 389 \\
\text { s } & 636 \\
\text { s } & 1,370 \\
& \\
\text { s } & 517 \\
\text { s } & 25 \\
\text { s } & 62 \\
\text { s } & 28 \\
\text { s } & 2,614\end{array}$ & $\begin{array}{cc}\text { s } & 6,225 \\
\text { s } & 1,232 \\
\text { s } & 849 \\
\text { s } & 39 \\
\text { s } & 1 \\
\text { s } & 0 \\
\text { s } & 1,256 \\
\text { s } & 188 \\
& \\
\text { s } & 477 \\
\text { s } & 888 \\
\text { s } & 888 \\
& \\
\text { s } & 290 \\
\text { s } & 78 \\
\text { s } & 20 \\
\text { s } & 18 \\
\text { s } & 2,472\end{array}$ & $\begin{array}{cc}\text { s } & 8,312 \\
\text { s } & 1,653 \\
\text { s } & 1,021 \\
\text { s } & 54 \\
\text { s } & 8 \\
\text { s } & 23 \\
\text { s } & 1,383 \\
\text { s } & 183 \\
& \\
\text { s } & 458 \\
\text { s } & 764 \\
\text { s } & 1,903 \\
& \\
\text { s } & 681 \\
\text { s } & 38 \\
\text { s } & 108 \\
\text { s } & 36 \\
\text { s } & 2,265\end{array}$ \\
\hline $\begin{array}{l}\text { III. Substance Abuse } \\
\text { Outpatient Visit } \\
\text { Alc/Narc Anonymous Meeting }\end{array}$ & $\begin{array}{l}\$ 75 \\
\$ 10\end{array}$ & $\begin{array}{cc}\$ & 290 \\
\$ & 235 \\
\$ & 55\end{array}$ & $\begin{array}{lc}S & 490 \\
S & 452 \\
S & 38\end{array}$ & $\begin{array}{lc}\$ & 409 \\
\$ & 314 \\
\$ & 95\end{array}$ & $\begin{array}{lc}S & 451 \\
\$ & 368 \\
S & 83 \\
\end{array}$ \\
\hline $\begin{array}{l}\text { IV. Medical \& Dental } \\
\text { Outpatient Clinic Visit } \\
\text { Inpatient Hospital Day } \\
\text { Emergency Room Visit } \\
\text { Dental Visit }\end{array}$ & $\begin{array}{lc}S & 114 \\
S & 452 \\
S & 181 \\
5 & 82\end{array}$ & $\begin{array}{lc}\text { S } & 1,448 \\
\mathbf{S} & 930 \\
\mathbf{S} & 0 \\
\mathbf{S} & 87 \\
\mathbf{S} & 431\end{array}$ & $\begin{array}{lc}\mathbf{S} & 1,284 \\
\mathbf{S} & 538 \\
\mathbf{S} & 289 \\
\mathbf{S} & 92 \\
\mathbf{S} & 365\end{array}$ & $\begin{array}{lr}\text { S } & 1,503 \\
\mathbf{S} & 502 \\
\mathbf{S} & 332 \\
\mathbf{S} & 230 \\
\mathbf{S} & 440\end{array}$ & $\begin{array}{lc}\text { s } & 1,172 \\
\text { s } & 656 \\
\text { S } & 0 \\
\text { s } & 118 \\
\text { s } & 398\end{array}$ \\
\hline
\end{tabular}

'Service counts based on a combination of SDF records and RI records.

${ }^{2}$ Medication costs were calculated in one of two ways. For neuroleptic drugs, a daily chlorpromazine equivalent dosage factor (daily dosage in milligrams divided by 100) was calculaled for each individua (e.g., if an individual received $550 \mathrm{mb} / \mathrm{day}$, their dosage factor was $550 / 100=5.5$ ). This factor was them multiplied by the average cost for $100 \mathrm{mg} /$ day of chlorpromazine for an entire year. For all other drugs (anti-depressents, anxiolytes, etc.), the annual cost of an average daily dosage was calculated. In both cases, average group (i.e., control or experimental) costs for each medication were summed to yield an average annual cost of medications for each group. 


\begin{tabular}{|c|c|c|c|c|c|}
\hline Monetized Costs & \$/Unit & $\begin{array}{l}\text { Control } \\
(\mathrm{n}=63)\end{array}$ & $\begin{array}{l}\text { Exper } \\
(\mathrm{n}=138)\end{array}$ & $\begin{array}{l}\text { Control } \\
(n=63)\end{array}$ & $\begin{array}{l}\text { Exper } \\
(\mathrm{a}=138)\end{array}$ \\
\hline $\begin{array}{l}\text { I. Residential Mental Healtb Care }{ }^{2} \\
\text { Community Inpatient Day } \\
\text { State Psych. Center Inpatient Day } \\
\text { Supervised Residential Day }\end{array}$ & $\begin{array}{lc}\$ & 388 \\
\$ & 388 \\
\$ & 72 \\
\end{array}$ & $\begin{array}{l}\text { S } 89,994 \\
\text { S } 438 \\
\text { \$ } 87,071 \\
\text { \$ } 2,484 \\
\end{array}$ & $\begin{array}{r}\$ 74,364 \\
\$ 1,034 \\
\$ 70,561 \\
\$ 2,499 \\
\end{array}$ & $\begin{array}{l}\$ 70,051 \\
\$ 1,467 \\
\$ 64,080 \\
\$ 4,504 \\
\end{array}$ & $\begin{array}{l}\$ 53,992 \\
\$ 2,988 \\
\$ 48,428 \\
\$ 2,576 \\
\end{array}$ \\
\hline $\begin{array}{l}\text { Social and Legal Services } \\
\text { DSS Case Management Hour } \\
\text { Religious Counselling Hour } \\
\text { Jail Night } \\
\text { Legal Contact } \\
\text { Probation Contact } \\
\text { Court Contact } \\
\text { Police Contact } \\
\text { Arrest } \\
\text { Other Services }\end{array}$ & $\begin{array}{lc}\text { \$ } & 27 \\
\text { \$ } & 30 \\
\text { \$ } & 95 \\
\text { \$ } & 109 \\
\text { \$ } & 25 \\
\text { \$1, } & 089 \\
\text { \$ } & 42 \\
\text { \$ } & 119 \\
\text { \$ } & 42\end{array}$ & 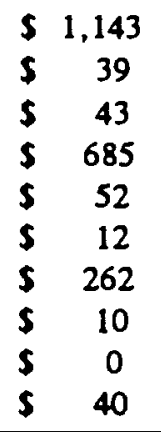 & $\begin{array}{lc}\text { S } & 546 \\
\text { S } & 18 \\
\text { S } & 23 \\
\mathbf{S} & 0 \\
\mathbf{S} & 97 \\
\mathbf{S} & 25 \\
\mathbf{S} & 283 \\
\mathbf{S} & 32 \\
\mathbf{S} & 31 \\
\mathbf{S} & 37\end{array}$ & $\begin{array}{lc}\text { S } & 877 \\
\text { S } & 33 \\
\text { S } & 0 \\
\text { S } & 699 \\
\text { s } & 54 \\
\text { S } & 61 \\
\text { S } & 0 \\
\text { s } & 31 \\
\text { s } & 0 \\
\text { S } & 0\end{array}$ & $\begin{array}{lc}\text { s } & 875 \\
\text { s } & 31 \\
\text { s } & 11 \\
\text { S } & 250 \\
\text { s } & 96 \\
\text { s } & 13 \\
\text { s } & 409 \\
\text { s } & 5 \\
\text { s } & 30 \\
\text { s } & 31\end{array}$ \\
\hline $\begin{array}{l}\text { VI. Non-Mental Health Residence and } \\
\text { Maintenance }\end{array}$ & & S 5,884 & $\$ 6,167$ & S 4,653 & S 6,588 \\
\hline Monetized Total Costs & & $\$ 105,733$ & 591,183 & $\$ 86.190$ & $\$ 73,655$ \\
\hline
\end{tabular}

Source: Reed, et al. (1993) Table 1.

1.Data come from the SDF and the Resource Index (RI) - the latter was available for the 127 subjects who completed first and second year follow-up protocols, counts for medical, social, and mental health services outside of public mental bealth system that were based on self-reports for the month preceding the follow-up interview.

2. Service counts based on combination of SDF records and RI reports. Supervised residential service counts represent a combination of community residence days and crisis residence days. 


\begin{tabular}{|c|c|c|c|c|}
\hline \multicolumn{5}{|c|}{$\begin{array}{l}\text { Appendix B. Probability of Being in The Sample Both Years for } \\
\text { Subsets } 1,2 \text {, and } 3^{1}\end{array}$} \\
\hline & $\begin{array}{l}\text { Subset } 1 \\
\text { SDF Data } 1\end{array}$ & $\begin{array}{c}\text { Subset } 2 \\
\text { Brief Survey } \\
\text { Protocol }\end{array}$ & $\begin{array}{l}\text { Subset } 3 \\
\text { Full Survey } \\
\text { Protocol }\end{array}$ & $\begin{array}{l}\text { Prob. of } \\
\text { Enrolling }\end{array}$ \\
\hline \multicolumn{5}{|l|}{ Explanatory Var: } \\
\hline $\begin{array}{l}\text { Treatment Var } \\
\text { EXP }\end{array}$ & $\begin{array}{c}0.39 \\
(0.26)\end{array}$ & $\begin{array}{l}-0.10 \\
(0.20)\end{array}$ & $\begin{array}{l}-0.11 \\
(0.19)\end{array}$ & $\begin{array}{l}4.37^{*} \\
(2.67)\end{array}$ \\
\hline $\begin{array}{l}\text { Personal Char. } \\
\text { AGE } \\
\text { FEM } \\
\text { WHITE }\end{array}$ & $\begin{array}{c}-0.00 \\
(0.01) \\
0.16 \\
(0.28) \\
0.78 * * \\
(0.27) \\
\end{array}$ & $\begin{array}{l}-0.00 \\
(0.01) \\
0.13 \\
(0.20) \\
-0.17 \\
(0.21) \\
\end{array}$ & $\begin{array}{c}0.01 \\
(0.01) \\
0.22 \\
(0.19) \\
-0.21 \\
(0.20) \\
\end{array}$ & $\begin{array}{c}0.01 \\
(0.01) \\
0.11 \\
(0.25) \\
-0.08 \\
(0.27) \\
\end{array}$ \\
\hline $\begin{array}{l}\text { Baseline Health } \\
\text { ALCDRUG0 } \\
\text { GASPCT } \\
\text { SYMPTO } \\
\text { INPOPCT }\end{array}$ & $\begin{array}{c}-0.10 \\
(0.19) \\
2.18 \\
(1.37) \\
0.05 \\
(0.04) \\
0.15 \\
(0.37) \\
\end{array}$ & $\begin{array}{c}0.09 \\
(0.14) \\
-0.05 \\
(0.95) \\
-0.03 \\
(0.03) \\
0.66^{* *} \\
(0.26) \\
\end{array}$ & $\begin{array}{c}0.23^{*} \\
(0.14) \\
0.83 \\
(0.94) \\
-0.05 \\
(0.03) \\
0.45^{*} \\
(0.26)\end{array}$ & $\begin{array}{l}-0.14 \\
(0.17) \\
2.18 \\
(1.18)^{*} \\
-0.06^{*} \\
(0.04) \\
-0.80^{* *} \\
(0.32)\end{array}$ \\
\hline $\begin{array}{l}\text { Agency } \\
\text { Agency } 1 \\
\text { Agency } 2 \\
\text { Agency } 3 \\
\text { Agency } 4\end{array}$ & $\begin{array}{l}1.24^{* *} \\
(0.41) \\
0.72^{* *} \\
(0.33) \\
0.86^{* *} \\
(0.35) \\
-0.06 \\
(0.72)\end{array}$ & $\begin{array}{c}0.68 * * \\
(0.27) \\
0.06 \\
(0.25) \\
0.23 \\
(0.26) \\
0.00 \\
(0.00)\end{array}$ & $\begin{array}{l}0.23 \\
(0.25) \\
-0.16 \\
(0.25) \\
-0.07 \\
(0.26) \\
0.00 \\
(0.00)\end{array}$ & $\begin{array}{l}0.25 \\
(0.33) \\
-0.48 \\
(0.34) \\
-0.03 \\
(0.30) \\
-0.56 \\
(0.80)\end{array}$ \\
\hline Intercept & $\begin{array}{c}1.20 \\
(0.94)\end{array}$ & $\begin{array}{l}-0.02 \\
(0.66)\end{array}$ & $\begin{array}{l}-0.27 \\
(0.65)\end{array}$ & $\begin{array}{l}-4.90^{*} \\
(2.79)\end{array}$ \\
\hline $\begin{array}{l}\text { Log Likelihood } \\
\text { Ratio }(-2 x) \text { : }\end{array}$ & 24.73 & 15.50 & 14.87 & 99.76 \\
\hline
\end{tabular}

$* *-\mathrm{t}>=1.96 *-\mathrm{t}>=1.67$ (standard errors in parenthesis)

$1_{n=221}$ for all probits. 


\section{Bibliography}

Abowd, John, "Program Evaluation", Chicago: Economics Research Center/NORC 1983.

Ashenfelter, Orley and D. Card, "Using the Longitudinal Structure of Earnings to Estimate the Effect of Training Programs", Review of Economics and Statistics 1985, pp. 648 - 660.

Babigian, H.M., O.S. Mitchell, P.E. Marshall, S.K. Reed, "A Mental Health Capitation Experiment: Evaluating the Monroe-Livingston Experience", in R. G. Frank and W.G. Manning Jr. (eds): Economics and Mental Health. Baltimore and London: John Hopkins University Press 1991, pp. 307-331.

Chamberlain, G., "Panel Data," in Z. Griliches and M. Intriligator, eds., Handbook of Econometrics. Amsterdam: North-Holland 1983.

Christianson, Jon B., F.C. Osher, "Health Maintenance Organizations, Health Care Reform, and Persons with Serious Mental Illness", Hospital and Community Psychiatry. 45:9 1994, pp. 898-905.

Christianson, Jon B., D.Z. Gray, "What CMHCs Can Learn from Two States' Efforts to Capitate Medicaid Benefits", Hospital and Community Psychiatry. 45:8 1994, pp. 777-781.

Christianson, Jon B., N. Lurie, M. Finch, I. Moscovice, D. Hartley, "Use of CommunityBased Mental Health Programs by HMOs: Evidence from a Medicaid Demonstration", American Journal of Public Health. 82:6, 1992, pp. 790-795.

Christianson, Jon B., Muriel S. Linehan, "Capitated Payments for Mental Health Care: The Rhode Island Programs", Community Mental Health Journal. 25:2 Summer, 1989, pp.121-131.

Christianson, Jon B., N. Lurie, M. Finch, I. Moscovice, "Mandatory Enrollment of MedicaidEligible Mentally Ill Persons in Prepaid Health Plans: The Minnesota Demonstration Project", Administration and Policy in Mental Health. 16:2 1988, pp. 51-63.

Fendell, Susan, "Mental Health Managed Care; MHMA Report Card Mixed Conflict Between Profits and Consumers", Advisor. Spring 1994, pp.4-11.

Hargreaves, William A., "A Capitation Model for Providing Mental Health Services in California", Hospital and Community Psychiatry. 43:3 1992, pp. 275-277.

Harrow, B.S., and R.P. Ellis, "Mental Health Providers' Response to the Reimbursement System", in R.G. Frank and W.G. Manning, Jr. (eds): Economics and Mental Health, Baltimore and London: John Hopkins University 1992, pp. 19-39. 
Hausman, J.A. and D. Wise, "Attrition Bias in Experimental and Panel Data: the Gary Income Maintenance Experiment", Econometrica, 47, pp. 455-473, (1979).

Heckman, J.J., "Sample Selection Bias as a Specification Error", Econometrica. 47 1979, pp. 153-161.

Heckman, J.J., Hotz, J., "Choosing Among Alternative Nonexperimental Methods for Estimating the Impact of Social Programs", Journal of American Statistical Assoc.. V. 84. 1989, pp. 733-750.

Jakubson, George, "The Sensitivity of Labor Supply Parameter Estimates to Unobserved Individual Effects: Fixed- and Random-Effects Estimates in a Nonlinear Model Using Panel Data". Journal of Labor Economics. 1988, pp. 302-29.

Johnson, Allan N., Bryan Down, Nora E. Morris, and Nicole Lurie. "Differences in Inpatient Resource Use by Type of Health Plan", Inquiry 26. Fall 1989, pp. 388-398.

Luft, H.S., "Assessing the Evidence on HMO Performance". Milbank Memorial Fund Quarterly. 58(4) 1980, pp. 501-36.

Lurie, Nicole, Moscovice, I.S., Finch, M., Christianson, J.B., Popkin, M.K., "Does Capitation Affect the Health of the Chronically Mentally Ill?". Journal of the American Medical Association. 267, \# 24 1992, pp. 3300-3304.

Manning, Willard G. Jr., and Kenneth B. Wells, "Preliminary Results of a Controlled Trial of the Effect of a Prepaid Group Practice on the Outpatient Use of Mental Health Services", Joumal of Human Resources. XXI*3 1987, pp. 293-317.

Manning, Willard G. Jr., and G.A. Goldberg, W.H. Rogers, and J.P. Newhouse. "A Controlled Trial of the Effect of a Prepaid Group Practice on Use of Services". New England Journal of Medicine, 310(23):1505-1510. (1984).

Mauch, D. "An Early Effort at Managed Care". New Directions for Mental Health Services. 43 1989, pp. 55-64.

McGuire, Thomas G., "Research on Economics and Mental Health: The Past and Future Prospects, in R.G. Frank and W.G. Manning, Jr. (eds): Economics and Mental Health. Baltimore and London: John Hopkins University 1992, pp. 1-12.

Ridder, Geert, "Attrition in Multi-Wave Panel Data", in J. Hartof, G. Ridder, and J. Theeuwes (eds): Panel Data and Labor Market Studies. North Holland: Elsevier Science Publishers B.V. 1990, pp. 45-67. 
Weisbrod, B., M.A. Test, and L.I. Stein, "Alternatives to Mental Hospital Treatment II: Economic Benefit-Cost Analysis", Archives of General Psychiatry. \#37 1980, pp. 400-405.

Weisbrod, B. "Benefit-Cost Analysis of a Controlled Experiment Treating the Mentally Ill", Journal of Human Resources. 16 1981, pp. 523-48.

Weisbrod, B., "A Guide to Benefit-Cost Analysis, as Seen through a Controlled Experiment in Treating the Mentally Il", in A. Rzain, E. Helpman, and E. Sadka (eds): Social Policy Evaluation. New York: Academic Press, pp. 5-42.

Weisman, E. "Managed Care: Delivering Quality and Value". Quality Review Bulletin. 14(12) 1988, pp. 372-374. 